\title{
Ergonomia Aplicada ao Projeto do Produto: O Ponto de Vista de Designers do Vestuário
}

\section{Ergonomics Applied to Product Design: The Fashion Designers' Point of View}

Crislaine Gruber ${ }^{1}$, Instituto Federal de Santa Catarina, Centro de Referência em Formação e Educação a Distância

Lizandra Garcia Lupi Vergara² ${ }^{2}$ Universidade Federal de Santa Catarina, Departamento de Engenharia de Produção

\section{RESUMO}

Este trabalho tem o objetivo de investigar a aplicação da ergonomia no processo de desenvolvimento de produtos do vestuário, do ponto de vista dos designers. Para isso, foram realizadas entrevistas semiestruturadas com 19 designers. As entrevistas foram gravadas e transcritas para realização de análise de conteúdo, baseada em três categorias: conceito de ergonomia; abordagem da ergonomia na formação acadêmica e na vivência profissional; aplicação da ergonomia no desenvolvimento de produtos. Foi constatado que a maioria dos participantes compreende o conceito de ergonomia e considera que ela é aplicada no processo de desenvolvimento de produtos do vestuário, contudo essa aplicação dá-se de forma intuitiva. Além disso, os participantes entendem que a aplicação da ergonomia e a obtenção de dados antropométricos dos usuários são atividades desenvolvidas apenas pelos modelistas. Acredita-se que é necessário abordar a ergonomia na formação profissional dos designers do vestuário, a fim de tornar essa aplicação sistemática e efetiva, afetando a satisfação dos usuários de forma positiva e, consequentemente, aumentando a competitividade das empresas.

Palavras-chave: Design do vestuário. Design de moda. Produto ergonômico. Engenharia do produto.

\section{ABSTRACT}

This paper aims to investigate the application of ergonomics in the fashion design process, from the designers' point of view. We conducted semistructured interviews with 19 designers. The interviews were recorded and transcribed for further content analysis, which was based on three categories: ergonomics concept; approach to ergonomics in academic training and professional experience; application of ergonomics in product development. It was found that most of the participants understand the concept of ergonomics and consider that it is currently?? applied in the fashion design process. However, we concluded that this application is intuitive. In addition, participants understand that the application of ergonomics and obtaining anthropometric data from users are activities developed only by patternmaking professionals. It is believed that it is necessary to approach ergonomics in the professional training of fashion designers to make this application systematic and effective, raising users' satisfaction and, consequently, increasing the competitiveness of companies.
Editor Responsável: Prof. Dr. Hermes Moretti Ribeiro da Silva

Keywords: Clothing design. Fashion design. Ergonomic product. Product engineering.

1. Rua Duarte Schutel, 99, Florianópolis, Santa Catarina, 88015-640, crislaine.gruber@ifsc.edu.br; 2. 1.vergara@ufsc.br. GRUBER, C.; VERGARA, L.G.L. Ergonomia aplicada ao projeto do produto: o ponto de vista de designers do vestuário. GEPROS. Gestão da Produção, Operações e Sistemas, v. 14, n. 2, p. 149 - 170, 2019.

DOI: $10.15675 /$ gepros.v14i2.2211 


\section{INTRODUÇÃO}

A Associação Internacional de Ergonomia (IEA) define ergonomia tanto como uma disciplina científica preocupada com a compreensão das interações entre os humanos e os outros elementos de um sistema quanto como um ofício que aplica teoria, princípios, dados e métodos de desenvolvimento para otimizar o bem-estar humano e a performance do sistema. Os ergonomistas, por sua vez, contribuem no desenvolvimento e na avaliação de atividades, práticas, produtos, ambientes e sistemas a fim de torná-los compatíveis com as necessidades, habilidades e limitações das pessoas.

Além de extensa aplicabilidade no setor industrial, a ergonomia apresenta relevância no cotidiano das pessoas. Iida e Buarque (2016) destacam que, inicialmente, as aplicações da ergonomia restringiram-se à indústria e ao setor militar e aeroespacial; hoje, contudo, elas expandem-se para a agricultura, o setor de serviços e a vida diária das pessoas. Nesse contexto, pode-se relacionar uma série de produtos com os quais as pessoas interagem cotidianamente, como, por exemplo, as roupas. Elas apresentam problemas que poderiam ser minimizados ainda no estágio inicial de desenvolvimento, caso fossem aplicados os conhecimentos acerca da ergonomia, conforme sugerem Karwowski e Marras (2005). A interação com o vestuário, quando inadequada, pode causar, além do desconforto, problemas de saúde. Apesar de serem feitas medidas acuradas do corpo humano há dois séculos, as pessoas ainda alegam ter problemas para encontrar roupas que sirvam bem. Pesquisa feita nos Estados Unidos constatou que 28 bilhões de dólares em roupas são devolvidos às lojas por problemas de tamanho e caimento (JONES, 2011).

Paschoarelli (2013, p.78) afirma que "a responsabilidade profissional de quem aplica a ergonomia depende de um suporte técnico-científico gerado em estudos da própria área ou de áreas correlatas". Para o autor, a aplicação da ergonomia no design de produtos depende de um embasamento teórico alicerçado na pesquisa científica da própria ergonomia ou de áreas correlatas, bem como de estudos focados na realidade efetiva dos problemas e com base em métodos que simulem esta realidade. Martins (2014) afirma que os designers de produtos de moda não conseguem equacionar a relação ergonomia, materiais têxteis e modelagem em produtos de moda.

Entendendo que o design do vestuário é uma área que necessita relacionar-se mais com a ergonomia, esta pesquisa tem como questão: de que maneira a ergonomia é aplicada no 
Ergonomia Aplicada ao Projeto do Produto: O Ponto de Vista de Designers do Vestuário

processo de desenvolvimento de produtos do vestuário? Com base na bibliografia pertinente, assume-se a hipótese de que os conhecimentos de ergonomia são aplicados de maneira não sistemática e intuitiva no desenvolvimento de produtos do vestuário. Dessa forma, o objetivo deste trabalho é investigar a aplicação da ergonomia no processo de desenvolvimento de produtos do vestuário.

\section{REFERENCIAL TEÓRICO}

\subsection{Conceito de ergonomia}

Melhorar a qualidade dos processos de trabalho, dos produtos e da vida no trabalho é uma dentre as diversas contribuições que a aplicação proficiente dos conhecimentos acerca da ergonomia pode trazer (KARWOWSKI; MARRAS, 2005). Pew (apud NEMETH, 2004) aponta seis objetivos para a área: aumentar a eficiência e a produtividade, aumentar a segurança, minimizar os gastos com treinamento de mão de obra, melhorar a proteção e a habitabilidade, aumentar o apelo ao usuário e flexibilizar o uso.

Paschoarelli (2013, p.89) afirma que "a ergonomia visa contribuir para minimizar os atritos nas relações entre tecnologia e usuários no que tange às atividades ocupacionais e da vida diária". O autor ressalta que "a aplicação da ergonomia no design de produtos é uma premissa indiscutível quando se pretende alcançar interfaces com elevados níveis de usabilidade, confiabilidade e segurança".

Iida e Buarque (2016) apresentam quatro contribuições da ergonomia, de acordo com a ocasião em que é feita: concepção, correção, conscientização e participação. A ergonomia de concepção representa a melhor situação, pois ocorre quando a contribuição ergonômica se faz durante o projeto do produto. A de correção é aplicada em situações reais para resolver problemas e, muitas vezes, a solução adotada não é completamente satisfatória, pois sua implementação pode ter um custo elevado. A ergonomia de conscientização procura capacitar os próprios trabalhadores para a identificação e correção dos problemas. Por fim, a ergonomia de participação envolve o próprio usuário na solução de problemas ergonômicos, compreendendo que ele possui um conhecimento prático que o projetista pode não ter. A ergonomia de concepção é a mais evidente no design do vestuário, processo que será abordado na próxima seção. 
Ergonomia Aplicada ao Projeto do Produto: O Ponto de Vista de Designers do Vestuário

\subsection{Design de vestuário}

Segundo Skepper, Straker e Pollock (2000), o processo de design corresponde a uma série sistemática de ações que são feitas para projetar um produto, um sistema ou um projeto. Para Pires (2004, p.4), "fazer design é designar cores, formas, materiais, funções e emoções, pensando de modo consciente e responsável.” Bürdek (2010) destaca problemas que o design deverá sempre atender: visualizar progressos tecnológicos, tornar transparente o contexto da produção, do consumo e da reutilização, promover serviços e a comunicação, e, quando necessário, evitar produtos sem sentido, e priorizar a utilização e o fácil manejo de produtos.

Pires $(2004$, p.2) afirma que "é recente a adoção do termo design para a formação e a profissão de quem concebe produtos de moda". Para a autora, desenvolver esses produtos é uma atividade multidisciplinar, ideia corroborada por Sanches (2014), segundo a qual a concepção de produtos de moda será mais sólida quando for orientada pelos princípios do design, devido à abrangência e multidisciplinaridade desta atividade.

Gomes Filho (2006, p.29) conceitua o design de moda como "especialidade ou área de atuação que envolve a criação, o desenvolvimento e a confecção de produtos da moda e atinge diversos segmentos de utilização, relacionados com o uso de objetos diretamente sobre o corpo". Ele é, na maioria das vezes, um design industrial, pois a maior parte dos produtos do vestuário é produzida industrialmente. Segundo o autor, o designer de moda deve utilizar seu repertório técnico e cultural, além de buscar informações de outras naturezas para projetar: conceitual, cultural, socioeconômica, política, tecnológica, público-alvo, etc. Para Pires (2004, p.1), o designer de moda "projeta conciliando aspectos de inovação dos materiais e das tecnologias, com os aspectos das interpretações culturais dos grupos sociais e das comunidades, integrando componentes estéticos, econômicos e competitivos".

A Tabela 1 sintetiza os processos de design do vestuário apresentados por diferentes autores. A pesquisa ou planejamento representa o início do processo em todos os casos. Durante esta etapa, são coletados e analisados os dados que subsidiarão as decisões durante o restante do processo. Dentre eles está a análise de vendas das coleções anteriores. Por meio de relatórios de vendas ou de contato com os representantes comerciais, pode-se detectar modelos mais vendidos e menos vendidos, bem como cores mais aceitas e menos aceitas, dentre outros aspectos relevantes para o desenvolvimento (SANCHES, 2014; TREPTOW, 2013; MATHARU, 2011). Sanches (2014) lista dados do público-alvo que servem de input no processo de design do vestuário, de modo a atender suas necessidades físicas e psíquicas: GEPROS. Gestão da Produção, Operações e Sistemas, v. 14, nº 2, p. 149 - 170, 2019 
faixa etária, poder aquisitivo, atividades cotidianas, preferências de estilo, atividades de lazer, configuração corporal, atitude de vida. Para a autora, os criadores devem filtrar e interpretar as informações para canalizá-las em produtos atrativos e eficazes segundo parâmetros técnicos, econômicos, mercadológicos e, principalmente, humanos e sociais. O destaque dado pela autora para os fatores humanos e sociais tem forte relação com a aplicação da ergonomia no vestuário. Relaciona-se com a ergonomia também a etapa de prova dos produtos, fundamental para refinar e confirmar proporções exatas, posicionamento de detalhes, movimento e aparência geral, bem como para avaliar quesitos de conforto, vestibilidade e segurança (RENFREW; RENFREW, 2010; SANCHES, 2014).

Tabela 1 - Fases do processo de design do vestuário.

\begin{tabular}{|c|c|c|c|c|c|}
\hline Fases & $\begin{array}{l}\text { Sorger; } \\
\text { Udale } \\
(2009)\end{array}$ & $\begin{array}{c}\text { Renfrew; } \\
\text { Renfrew } \\
(\mathbf{2 0 1 0})\end{array}$ & $\begin{array}{c}\text { Matharu } \\
\text { (2011) }\end{array}$ & $\begin{array}{c}\text { Treptow } \\
\text { (2013) }\end{array}$ & $\begin{array}{c}\text { Sanches } \\
\text { (2014) }\end{array}$ \\
\hline \multicolumn{6}{|l|}{ Pesquisa } \\
\hline \multicolumn{6}{|c|}{ Definição de segmento e público-alvo } \\
\hline \multicolumn{6}{|l|}{ Planejamento } \\
\hline \multicolumn{6}{|l|}{ Criação } \\
\hline \multicolumn{6}{|l|}{ Geração de alternativas } \\
\hline \multicolumn{6}{|l|}{ Design } \\
\hline \multicolumn{6}{|l|}{ Desenvolvimento } \\
\hline \multicolumn{6}{|l|}{ Avaliação e detalhamento } \\
\hline \multicolumn{6}{|l|}{ Prototipagem } \\
\hline \multicolumn{6}{|l|}{ Produção } \\
\hline \multicolumn{6}{|l|}{ Edição } \\
\hline \multicolumn{6}{|l|}{ Apresentação } \\
\hline \multicolumn{6}{|l|}{ Lançamento } \\
\hline Promoção e comercialização & & & & & \\
\hline
\end{tabular}

Fonte: elaborada pelas autoras (2017) a partir de: Sorger e Udale (2009), Renfrew e Renfrew (2010), Matharu (2011), Treptow (2013) e Sanches (2014).

\subsection{Ergonomia no vestuário}

Apesar de existirem esforços para fomentar o desenvolvimento de produtos do vestuário mais acessíveis e usáveis por todos, Martins (2005) afirma que as metodologias da área desconsideram a usabilidade e a ergonomia. A autora defende que a ergonomia deve integrar a etapa inicial de concepção de qualquer produto, prevenindo equívocos e disfunções GEPROS. Gestão da Produção, Operações e Sistemas, v. 14, nº 2, p. 149 - 170, 2019. 
Ergonomia Aplicada ao Projeto do Produto: O Ponto de Vista de Designers do Vestuário

no produto, economizando tempo e recursos (MARTINS, 2014). Nesse sentido, Gonçalves e Lopes (2006) sugerem que, além do profissional de moda, é necessário um profissional de ergonomia na concepção de produtos do vestuário, evitando custos adicionais com a correção.

Pires (2004) afirma que o designer de moda deve estudar o corpo e a moda conforme os conceitos da ergonomia, relacionada à segurança e ao conforto, cada vez mais definitivos como critérios de compra. "Para que o vestuário seja eficaz e confortável o estilista precisa ter conhecimento dessa estrutura móvel que é o corpo humano.” (JONES, 2011, p.78).

Para Silveira (2006), a ergonomia aplica-se de forma direta no caso de produtos do vestuário, fundamentando-se em outras ciências e envolvendo aspectos funcionais, psicológicos, de saúde, de segurança e a estética, o que demanda a participação de diferentes profissionais em seu projeto. A autora afirma que a roupa projetada ergonomicamente garante conforto, possibilita os movimentos do corpo e causa a sensação de "bem-estar" e de "estar" na moda. Rosa (2011) sistematizou oito qualidades ergonômicas a serem consideradas na concepção de produtos do vestuário: facilidade de manuseio, adaptação antropométrica, fornecimento claro de informações, facilidade para vestir e despir, facilidade de movimentos, conforto, segurança e capacidade de guardar coisas.

Gonçalves e Lopes (2006, p.23) acreditam que "os estudos ergonômicos contribuem com a área do vestuário em geral para auxiliar na evolução e solução dos projetos de produto de uso cotidiano [...] ao considerarem o bem-estar do homem na realização das tarefas no diaa-dia”. As autoras corroboram o apresentado por Silveira (2006) ao afirmarem que a criação e o desenvolvimento do produto de moda-vestuário necessitam do conhecimento de diferentes áreas, como anatomia humana, fisiologia, antropometria, psicologia e sociologia, a fim de melhorar a concepção de produtos que façam íntima relação com o usuário. Pires (2004) também apresenta diversos fatores que devem ser considerados no desenvolvimento de produtos de moda, dentre eles a ergonomia: qualidade formal do produto; adequação ao uso (conforto, praticidade, ergonomia); inovação; confiabilidade; evolução tecnológica; características culturais e socioeconômicas; estudo dos materiais e processos de fabricação; racionalização dos componentes; melhor utilização dos recursos em capacidade instalada; ética e respeito ao meio ambiente.

Paschoarelli (2013) destaca o vestuário como um exemplo de setor no qual são constatados problemas devido à falta de normatização, gerando constrangimentos a muitos usuários. $\mathrm{O}$ autor afirma que os aspectos físicos parecem ser considerados menos importantes GEPROS. Gestão da Produção, Operações e Sistemas, v. 14, nº 2, p. 149 - 170, 2019. 
Ergonomia Aplicada ao Projeto do Produto: O Ponto de Vista de Designers do Vestuário

ou até mesmo dispensáveis, pois são habitualmente associados aos princípios antropométricos e de dimensionamento físico-linear das interfaces. Boueri (2014, p.347) afirma que "o dimensionamento adequado do vestuário é tão importante para o usuário quanto os aspectos conforto, segurança, proteção e estética.” O autor destaca que no Brasil tem-se trabalhado com diferentes padrões dimensionais, devido à falta de normatização, e que o designer deve conhecer os dados que influenciam no dimensionamento do vestuário, bem como verificar a qualidade e a confiabilidade dos dados antropométricos a serem aplicados no projeto.

Segundo Nishimura, Merino e Amaral (2016), no Brasil, ainda não se tem padrões de medidas, instrumentos apropriados para medições precisas. E, além disso, a extensão do país e a miscigenação da população resultam em uma grande variabilidade de biótipos que precisa ser atendida pela indústria do vestuário. Essa preocupação é evidenciada também no trabalho de Widyanti et al. (2015). Os autores realizaram pesquisa antropométrica com duas etnias da Indonésia e constataram uma diferença significativa entre os dados advindos de cada uma das etnias estudadas. $\mathrm{O}$ trabalho corrobora a importância da antropometria para o desenvolvimento de roupas e móveis. Em seu estudo, os autores afirmam que considerando que os dados antropométricos utilizados no design do vestuário apresentam diferença significativa entre as duas etnias pesquisadas, Sundanese e Minangkabau, fica claro que o tamanho universal de roupas, advindo de dados da primeira etnia, não será adequado para pessoas da segunda etnia.

Gruber e Alves (2011) sinalizaram a importância das tabelas de medidas como peçachave na confecção de artigos do vestuário e no sucesso de sua comercialização. As autoras afirmam que a falta de homogeneidade entre as nomenclaturas, grades e medidas específicas das tabelas de medidas dificulta a etapa de modelagem, de grande importância para o setor produtivo do vestuário, e indicam a necessidade de realização de um senso antropométrico com a participação das diferentes tipologias dos perfis brasileiros. Sabrá et al. (2013) relatam o estudo antropométrico da população brasileira que está sendo realizado pelo Senai Cetiqt e que apresentará uma referência não apenas para a indústria do vestuário, mas para todas as que necessitam de medidas do corpo humano para desenvolver seu trabalho.

$\mathrm{Na}$ área da aviação, por exemplo, tem-se o trabalho de Poirson e Parkinson (2014), que reiteram a importância da utilização dos dados antropométricos pela indústria - para desenvolver móveis, ferramentas, roupas, dentre outros produtos que são dependentes das medidas humanas - devido às diferenças existentes entre as pessoas. Barroso et al. (2005) GEPROS. Gestão da Produção, Operações e Sistemas, v. 14, nº 2, p. 149 - 170, 2019 
Ergonomia Aplicada ao Projeto do Produto: O Ponto de Vista de Designers do Vestuário

realizaram uma coleta desses dados em Portugal justificada pela relevância da sua aplicação no design de ferramentas, equipamentos, postos de trabalho e roupas. Jarosz (2000), por sua vez, traz a questão das pessoas idosas e da necessidade de os dados antropométricos atenderem adaptações de postos de trabalho, centros sociais, móveis, roupas, dentre outros para essa parcela da população.

Rosa (2011) afirma que os estudos relacionados à qualidade ergonômica do vestuário são recentes e pouco difundidos, portanto seu uso ocorre, muitas vezes, de forma intuitiva ou empírica. $\mathrm{O}$ autor identificou que na indústria de confecção do vestuário é comum os métodos restringirem-se aos profissionais que constroem seus saberes de forma empírica, o que resulta no pequeno número de estudos que sistematizam o uso da ergonomia na concepção do produto nesse setor produtivo. Esse uso intuitivo da ergonomia no processo de desenvolvimento também ocorre em outros processos de desenvolvimento de produto, conforme relatado por Skepper, Straker e Pollock (2000) em um estudo com engenheiros e designers. Uma das recomendações desses autores para que a ergonomia seja de fato incluída no processo de design é o treinamento dos engenheiros e designers no uso das informações de ergonomia, inclusive de dados antropométricos.

Martins (2014) afirma que um produto tende a ser descartado quando não atende às expectativas de seus usuários. Para Renfrew e Renfrew (2010), criatividade e usabilidade são interdependentes para o sucesso dos negócios de moda. Sanches (2014) destaca que a competitividade sobre as empresas determina que os produtos de moda sejam melhor adaptados às necessidades e aos desejos dos consumidores. A partir desses autores, reafirmase a importância da ergonomia como disciplina que busca compreender e atender as expectativas e necessidades dos usuários a fim de atendê-las no projeto de produto. A Tabela 2 demonstra como a ergonomia pode ser incorporada ao processo de design de vestuário a partir dos estudos de Silveira (2006), Rosa (2011) e Sanches (2014).

Tabela 2 - Sugestões de incorporação da ergonomia no processo de design do vestuário.

\begin{tabular}{ll}
\hline Etapas & Sugestões \\
\hline Concepção & Inserir bolsos para mãos ou objetos. \\
& Desenvolver soluções, como fendas e aberturas, sem comprometer a segurança do usuário. \\
& Preparar produtos para atender diferentes biótipos.
\end{tabular}
Inserir mecanismos de abertura e fechamento do produto. 


\section{Ergonomia Aplicada ao Projeto do Produto: O Ponto de Vista de Designers do Vestuário}

\begin{tabular}{|c|c|}
\hline & Coletar medidas antropométricas dos usuários dos produtos. \\
\hline & Elaborar tabelas de medidas específicas para o público-alvo. \\
\hline & Harmonizar o modelo criado com as medidas do corpo humano. \\
\hline \multirow{3}{*}{$\begin{array}{l}\text { Escolha das } \\
\text { matérias-primas }\end{array}$} & Garantir que a roupa retorne a sua posição normal no corpo depois da realização de movimentos. \\
\hline & Substituir etiquetas por estampas. \\
\hline & Escolher matérias-primas de fácil manutenção. \\
\hline \multirow[t]{10}{*}{ Modelagem } & Seguir padrão estabelecido no projeto. \\
\hline & Realizar estudo de bases de modelagem que contemplem os movimentos do corpo. \\
\hline & Fazer os ajustes necessários nos moldes conforme os materiais e modos de fabricação utilizados. \\
\hline & Sinalizar a parte das costas com etiqueta. \\
\hline & Usar tabelas de medidas referenciais de roupa pronta. \\
\hline & Usar tabelas de medidas padronizadas do corpo humano. \\
\hline & Criar espaços no molde que atendam as dimensões do corpo humano. \\
\hline & Observar se as medidas estão de acordo com as informações da Ficha Técnica do Produto. \\
\hline & Desenvolver bases de modelagem para diferentes biótipos. \\
\hline & Usar o Desenho Técnico do Produto. \\
\hline Engenharia & $\begin{array}{l}\text { Adequar o produto para contemplar a especificidade de cada material ou processo utilizado e facilitar o } \\
\text { processo de fabricação. }\end{array}$ \\
\hline \multirow[t]{6}{*}{ Costura } & Seguir padrão estabelecido no projeto. \\
\hline & Conferir se tipo ou vida útil das agulhas de costura não compromete a segurança do produto. \\
\hline & Ajustar a tensão dos pontos de costura para cada tipo de material, acabamento ou recorte da peça. \\
\hline & Não esticar a peça na montagem, evitando alterações de medidas do produto. \\
\hline & Não costurar além do espaço previsto, alterando as medidas do produto. \\
\hline & Cuidar com as tensões da costura que dificultam o vestir e desvestir. \\
\hline \multirow[t]{8}{*}{ Testes } & Questionar o modelo de prova se produto gera insegurança. \\
\hline & Avaliar o comportamento das matérias-primas e dos acabamentos do produto. \\
\hline & Realizar a prova do produto em modelos vivos, observando seus movimentos. \\
\hline & $\begin{array}{l}\text { Testar o protótipo em integrante da equipe de desenvolvimento para apresentar suas considerações } \\
\text { sobre o produto. }\end{array}$ \\
\hline & Observar o nível de conforto em áreas de maior atrito, como pescoço, axila, etc. \\
\hline & Analisar ajuste e caimento da peça ao corpo. \\
\hline & Testar funcionamento dos dispositivos diretos de interação (fechos, regulagens, por exemplo). \\
\hline & Verificar sobre o vestir e desvestir. \\
\hline \multirow[t]{3}{*}{ Venda } & Informar ao usuário os cuidados necessários para que o produto seja seguro. \\
\hline & Informar dados importantes do produto no site da empresa. \\
\hline & Inserir informações nas embalagens. \\
\hline
\end{tabular}


Desenvolver material explicativo sobre uso do produto.

Fazer demonstração do produto.

Simplificar informações.

Usar informações conforme legislação vigente.

Usar material impresso.

Dispositivos de informação sobre uso e manutenção.

Função objetiva do produto.

Elaborar material informativo.

Utilizar etiquetas para fornecer informações sobre o produto aos usuários.

Fonte: elaborada pelas autoras (2017) a partir de: Silveira (2006), Rosa (2011) e Sanches (2014).

\section{PROCEDIMENTOS METODOLÓGICOS}

Esta pesquisa, qualitativa e exploratória, utilizou entrevistas semiestruturadas para coletar dados junto a designers de vestuário. Esses profissionais foram selecionados de forma não probabilística, por conveniência, de acordo com os seguintes critérios: 1) estar atuando com desenvolvimento de produtos do vestuário no momento de realização da pesquisa e 2) ter formação de nível superior na área de moda. A pesquisa foi aprovada pelo Comitê de Ética em Pesquisa com Seres Humanos da Universidade Federal de Santa Catarina. Todos os participantes foram convidados a responderem à entrevista e assinaram o Termo de Consentimento Livre e Esclarecido, concordando em fazer parte da amostra de forma voluntária, confidencial e anônima. A entrevista foi conduzida de acordo com o roteiro apresentado na Tabela 3.

Tabela 3 - Roteiro para condução das entrevistas semiestruturadas com os designers de vestuário.

1) Nome:

2) Sexo: feminino ( ) masculino ( )

3) Idade:

4) Formação (Tipo/ano de obtenção/instituição):

( ) Técnico:

( ) Graduação:

( ) Pós-graduação:

5) Cargo atual: ......................... Segmento: ...................... Empresa:

6) Tempo de atuação na área de desenvolvimento de produto de vestuário:

Geral:

$\mathrm{Na}$ empresa atual:

7) Para você, o que é ergonomia? (Induzir sobre a abordagem do conceito na formação acadêmica).

8) Você diria que a sua empresa ou você trabalha com ergonomia em alguma etapa da produção? Qual?

9) Como você obtém os dados antropométricos dos diferentes biótipos que compõem o público-alvo?

10) Quais os principais dados do público-alvo que você utiliza no processo de desenvolvimento de produtos?

11) Descreva seu processo de desenvolvimento de produtos (roteiro, procedimento).

Fonte: elaborada pelas autoras ( 2017).

GEPROS. Gestão da Produção, Operações e Sistemas, v. 14, nº 2, p. 149 - 170, 2019. 
Ergonomia Aplicada ao Projeto do Produto: O Ponto de Vista de Designers do Vestuário

Para tratamento dos dados coletados, foi utilizada a análise de conteúdo, organizada, segundo Bardin (2011), em três polos cronológicos:

- Pré-análise: consiste na escolha dos documentos, formulação de hipóteses e objetivos e elaboração de indicadores que fundamentam a interpretação final, tendo por objetivo sistematizar e tornar operacionais as ideias iniciais, estabelecendo um programa preciso da análise. Nesta pesquisa, os documentos analisados foram as transcrições das entrevistas. A hipótese inicial - "os conhecimentos de ergonomia são aplicados de maneira não sistemática e intuitiva no desenvolvimento de produtos do vestuário" - foi complementada pelas seguintes hipóteses: os designers de vestuário, em sua maioria, conhecem o conceito de ergonomia; os designers de vestuário, em sua maioria, consideram que a ergonomia é utilizada principalmente na fase de modelagem do produto de vestuário; os designers de vestuário, em sua maioria, não estão envolvidos na definição da tabela de medidas utilizada pela empresa. $\mathrm{O}$ objetivo desta análise é investigar a aplicação da ergonomia no processo de desenvolvimento de produtos do vestuário. Ainda na pré-análise, foram definidas as categorias para análise: conceito de ergonomia; abordagem da ergonomia na formação acadêmica e na vivência profissional; aplicação da ergonomia no desenvolvimento de produtos. A última atividade da pré-análise foi a preparação do material por meio da transcrição das entrevistas.

- Exploração do material: consiste em operações de codificação em função das regras previamente formuladas.

- Tratamento dos resultados, inferência e interpretação: consiste na proposição de inferências e interpretações a respeito dos objetivos propostos.

Para operacionalizar a análise de conteúdo, foi utilizada a proposta de Guerra (2012), a qual é apropriada para amostras de 15 a 20 sujeitos, como a desta pesquisa. A autora sugere as seguintes etapas para a condução da análise: 1) transcrição; 2) leitura das entrevistas; 3) construção das sinopses das entrevistas; 4) análise descritiva; 5) análise interpretativa. A transcrição, neste caso em que os participantes falam na primeira pessoa, deve ser integral e fiel ao que foi dito. Utilizou-se cerca de 20 minutos para realizar cada entrevista e uma hora para transcrevê-la. A segunda etapa, leitura das entrevistas, corresponde a uma leitura cuidadosa, na qual se sublinha algumas frases do texto a cor, utilizando cores diferentes para destacar uma temática da outra. Neste momento pode-se também resumir as entrevistas para a etapa posterior, a construção das sinopses. Estas têm como objetivo reduzir o montante de GEPROS. Gestão da Produção, Operações e Sistemas, v. 14, nº 2, p. 149 - 170, 2019. 
Ergonomia Aplicada ao Projeto do Produto: O Ponto de Vista de Designers do Vestuário

material a trabalhar identificando o corpus central da entrevista, permitir o conhecimento da totalidade do discurso, mas também de suas diversas componentes, facilitar a comparação longitudinal das entrevistas e ter a percepção da saturação das entrevistas. As sinopses são sínteses dos discursos, as quais contêm a mensagem essencial da entrevista e são fiéis ao que disseram os entrevistados.

As análises descritiva e interpretativa, últimas etapas da análise de conteúdo, visam, respectivamente, contar aos leitores o que disseram os entrevistados, agregando as diferentes lógicas do que foi contado nas diversas entrevistas, e fazer comparações, conceber novos conceitos e avançar com proposições teóricas potencialmente explicativas do fenômeno estudado (GUERRA, 2012). As etapas três a cinco representam o momento de tratamento dos resultados coletados por meio das entrevistas; a partir da construção das sinopses, começa-se a organizar o material coletado de uma forma coerente a fim de apresentá-lo aos leitores e de contribuir para a compreensão do tema da pesquisa. O uso de planilhas, de cores, de nuvem de palavras, quadros, dentre outros, auxiliará os pesquisadores e os leitores a visualizarem as descobertas da pesquisa. A partir daí, pode-se construir a discussão relacionando o que foi apontado pelos entrevistados e as relações percebidas no tratamento dos resultados com a literatura pertinente.

\section{RESULTADOS}

A pesquisa teve participação de 19 estilistas, sendo 18 mulheres e um homem, com idade entre 23 e 35 anos, totalizando uma média de 27,2 anos com desvio padrão de 2,74. Os participantes concluíram a graduação na área de moda entre 2008 e 2014. Cinco concluíram pós-graduação e outros cinco estão cursando. A Tabela 4 apresenta os participantes, identificados com os códigos que serão utilizados neste artigo, e os dados de atuação profissional. Observa-se que 13 trabalham apenas com público feminino e seis trabalham com feminino e masculino. Os segmentos com maior frequência na amostra são Lingerie (3), Beachwear (3) e Casual (3). O tempo de atuação na área de desenvolvimento de produtos de vestuário varia de dois a 12 anos, com média de cinco anos e cinco meses e desvio padrão de dois anos e sete meses, aproximadamente. Em relação ao tempo de atuação na área na empresa atual, varia de dois meses a seis anos e cinco meses, com média de dois anos e dez meses e desvio padrão de dois anos, aproximadamente. 
Tabela 4 - Breve descrição dos participantes do estudo.

\begin{tabular}{|c|c|c|c|}
\hline Participante & Segmento & Tempo de atuação na área & $\begin{array}{l}\text { Tempo de atuação na } \\
\text { empresa atual }\end{array}$ \\
\hline $\mathrm{P} 1$ & Jeanswear, tecido plano e malha feminino & 9 anos & 1 ano e 6 meses \\
\hline $\mathrm{P} 2$ & Geral feminino e masculino & 4 anos & 2 meses \\
\hline P3 & Beachwear feminino & 6 anos & 4 meses \\
\hline P4 & Infantil feminino e masculino & 6 anos & 2 anos aproximadamente \\
\hline P5 & Jeanswear feminino & 2 anos & 2 anos \\
\hline P6 & Beachwear feminino & 2 anos & 2 anos \\
\hline P7 & Infantil feminino e masculino & 6 anos e 5 meses & 6 anos e 5 meses \\
\hline P8 & Casual feminino & 8 ou 9 anos & 1 ano e 11 meses \\
\hline P9 & Tecido plano feminino & 7 anos & 2 anos e 10 meses \\
\hline $\mathrm{P} 10$ & Casual feminino & 4 anos aproximadamente & 2 anos e 6 meses \\
\hline P11 & Adulto feminino & 4 anos e 8 meses & 4 anos e 8 meses \\
\hline $\mathrm{P} 12$ & Fitness e fashion feminino e masculino & 5 anos aproximadamente & 5 anos aproximadamente \\
\hline $\mathrm{P} 13$ & Plus size feminino & 12 anos & 3 anos \\
\hline P14 & Contemporâneo feminino & 7 anos & 5 anos \\
\hline P15 & Lingerie e sleepwear feminino e masculino & 6 anos & 6 anos \\
\hline P16 & Lingerie e beachwear feminino & 2 anos e 6 meses & 2 anos e 6 meses \\
\hline P17 & Lingerie feminino & 2 anos e 6 meses & 2 anos e 6 meses \\
\hline P18 & Casual feminino & 6 anos & 5 anos \\
\hline P19 & Adulto feminino & 3 anos & 2 anos e 6 meses \\
\hline
\end{tabular}

Fonte: elaborada pelas autoras ( 2017).

\subsection{Conceito de ergonomia}

Dos 19 participantes, dez entendem que a ergonomia é a adequação dos produtos ao usuário, 11 a relacionam ao conforto e seis à modelagem do produto. As questões de encaixe do produto ao corpo, de funcionalidade e das medidas foram citadas por três participantes cada uma. Os termos: ajuste, bem-estar, caimento, padronização de medidas, qualidade e saúde foram citados, cada um, por dois participantes. Com uma ocorrência tem-se os temas: aderência, agilidade, anatomia, atender necessidades, comodidade, design, destreza, estudo do corpo, fisiologia, formas, interação, matéria-prima, movimentos, praticidade, público-alvo, segurança, saúde, tamanhos, tipos de corpos, uso, vestibilidade e vestir bem.

Duas participantes relacionaram a ergonomia ao trabalho, às condições de saúde e segurança dos trabalhadores na empresa. Três participantes utilizaram o termo estética, porém 
Ergonomia Aplicada ao Projeto do Produto: O Ponto de Vista de Designers do Vestuário

para destacar que a estética não se relaciona à ergonomia. A Figura 1 apresenta o painel de palavras relativo ao entendimento dos participantes pelo termo ergonomia. Ao centro e em tamanho maior encontram-se as temáticas mais citadas: conforto, adequação do produto ao usuário e modelagem.

Figura 1 - Painel de palavras representando a opinião dos designers acerca do conceito de ergonomia.

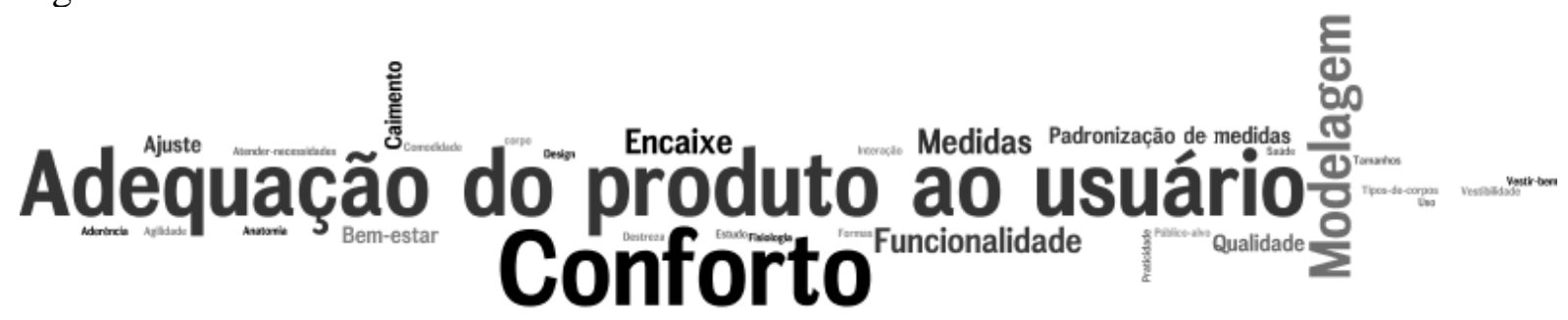

Fonte: elaborada pelas autoras ( 2017).

\subsection{Abordagem da ergonomia na formação acadêmica e na vivência profissional}

O conceito de ergonomia apresentado pelos participantes advém, para 13 participantes, da vivência profissional, e, para 13, da formação acadêmica. Sete participantes acreditam que advém tanto da formação acadêmica quanto da vivência profissional. Seis estilistas afirmaram que conheceram a ergonomia apenas na faculdade, e seis apenas na vivência profissional. Dentre estes, estão o P3 e o P10, que afirmaram, respectivamente: "é uma coisa que a gente aprende mais na prática" e "a gente vai descobrindo no dia a dia".

Dentre os participantes que afirmaram conhecer a ergonomia apenas de seus estudos acadêmicos, o P5 e o P8 afirmaram, respectivamente: "ergonomia foi uma matéria da faculdade na primeira ou segunda fase [...] e na indústria, dentro da empresa, tu não ouve falar de ergonomia" e "ergonomia, esse termo mais técnico, eu nunca ouço no meu trabalho [...] Na moda a gente não usa muito pelo menos o termo ergonomia". Dentre os participantes que declararam conhecer a ergonomia tanto da formação acadêmica quanto da vivência profissional, os P9, P17 e P18 afirmaram, respectivamente: "na parte acadêmica o estudo de ergonomia é muito sutil", "o termo eu aprendi na faculdade, mas acredito que eu use bastante no meu dia a dia" e "aprendi o conceito da universidade, mas acho que tive mais contato durante a vida profissional". 


\subsection{Aplicação da ergonomia no desenvolvimento de produtos do vestuário}

Dos 19 participantes, apenas um afirmou que não trabalha com ergonomia. Os participantes afirmaram que as etapas nas quais a ergonomia é aplicada durante o processo de desenvolvimento de produtos do vestuário são, principalmente, a modelagem e a prova dos produtos, conforme apresentado na Tabela 5. Algumas participantes detalharam casos nos quais consideram que estão aplicando a ergonomia: aplicação de caída de ombro em camisas, ajuste do volume do quadril na modelagem, sustentação dos seios com bojos, aros e tecidos mais firmes, utilização de tecido com elasticidade, reguladores para ajuste da roupa ao corpo, tecidos tecnológicos, tecidos com qualidade, tecidos peluciados, cuidado com os recortes e costuras da roupa.

Tabela 5 - Etapas do processo de desenvolvimento do vestuário nas quais a ergonomia é aplicada.

\begin{tabular}{lc}
\hline Etapa & Ocorrências \\
\hline Modelagem & 13 \\
Prova dos produtos & 6 \\
Concepção/Desenvolvimento & 5 \\
Escolha das matérias-primas & 5 \\
Pilotagem & 3 \\
Estudo antropométrico & 3 \\
Costura & 1 \\
Ficha técnica & 1 \\
Graduação dos moldes & 1 \\
Produção & 1 \\
Pós-vendas & 1 \\
\hline
\end{tabular}

Fonte: elaborada pelas autoras (2017).

Uma das participantes afirmou que existe uma relação direta entre atender os desejos das clientes e ter maior retorno financeiro. Para ela, desenvolver uma roupa que veste bem gera maiores resultados para a empresa do que considerar apenas o fator estético das roupas, pois a cliente quer estar bonita com conforto. Três participantes, ao serem questionadas sobre a aplicação da ergonomia, afirmaram "só desenho", "só crio", "apenas defino o que quero para o produto", desatrelando a aplicação da ergonomia à etapa de concepção e relacionandoa apenas à modelagem dos produtos. 
Ergonomia Aplicada ao Projeto do Produto: O Ponto de Vista de Designers do Vestuário

Sete participantes afirmaram não ter envolvimento com a obtenção dos dados antropométricos do público-alvo: cinco trabalham em empresas de grande porte, um com consultoria para desenvolvimento de coleções de moda e um em uma empresa que terceiriza a etapa de modelagem, ficando sob a responsabilidade de outras empresas a definição das tabelas de medidas. Os participantes que afirmam não se envolver com a obtenção dos dados antropométricos destacam que essa é a uma atribuição do setor de modelagem.

Catorze participantes destacaram a utilização da prova dos produtos na etapa de definir as medidas, como subsídio para o desenvolvimento. Três participantes, proprietárias das empresas que trabalham, afirmaram que fazem as provas dos produtos em si mesmas. As três empresas em questão existem há pouco mais de dois anos.

Quatro participantes comentaram sobre as diferenças de biótipos existentes entre as regiões do país, o que dificulta a definição de uma tabela de medidas padrão. Uma participante que trabalha com o público infantil destacou nessa questão a necessidade de cuidar com os comprimentos das roupas, para que não fiquem muito curtas e "indecentes", e que proporcionem conforto para a criança. A participante que trabalha com o segmento fitness destacou que na empresa em que trabalha as roupas são produzidas apenas nos tamanhos $\mathrm{P}$ e M para o público feminino, pois o público-alvo tem um biótipo bem definido.

Duas empresas de grande porte nas quais participantes da pesquisa trabalham realizam estudos antropométricos de seus usuários a fim de definirem tabelas de medidas mais adequadas ao público-alvo. Em uma dessas empresas, foi utilizada a tecnologia do body scanner. Outras empresas estudadas também realizam estudos sobre suas tabelas de medidas por meio de análise de tabelas encontradas na literatura ou por meio de prova com clientes. Uma delas, que trabalha com tamanhos grandes, realizou diversas adaptações nas tabelas de medidas a fim de aumentar a diversidade de tamanhos e corrigir falhas na modelagem para atender melhor seu público-alvo.

A Tabela 6 apresenta os dados mais utilizados pelos estilistas entrevistados para o desenvolvimento de produtos do vestuário, por ordem de ocorrência. Faixa etária e histórico de vendas foram os mais citados. 
Tabela 6 - Dados do público-alvo utilizados no desenvolvimento de produtos.

\begin{tabular}{lc}
\hline Dados & Ocorrências \\
\hline Faixa etária & 8 \\
Histórico de vendas & 8 \\
Comportamento & 4 \\
Classe social & 4 \\
Poder aquisitivo & 4 \\
Sexo & 4 \\
Tendências de moda & 4 \\
Estilo de vida & 3 \\
Perfil de consumo & 3 \\
Região do país & 3 \\
Tipo de produto & 2 \\
Tipo de público & 2 \\
\hline
\end{tabular}

Fonte: elaborada pelas autoras (2017).

\section{DISCUSSÕES}

O entendimento por ergonomia demonstrado pela maioria dos estilistas entrevistados é condizente com o apresentado pelas principais referências no assunto. Cerca de metade dos participantes compreendem a ergonomia como a adequação dos produtos ao usuário, a maioria a relacionam com o conforto e seis com a modelagem do vestuário, ou seja, com questões de ajuste da roupa ao corpo (JONES, 2011; SILVEIRA, 2006; PIRES, 2004; ROSA, 2011).

Alguns entrevistados afirmam que a estética é uma questão importante no desenvolvimento do produto, mas que não tem relação com a ergonomia. Pew (apud NEMETH, 2004) aponta como um objetivo para a área aumentar o apelo ao usuário, o que pode se relacionar à aparência do produto. Além disso, diversos fatores influenciam na interação entre o produto e o usuário para que ela se torne ergonômica; a aparência pode ser um desses fatores. Desta forma, tal como observado por Skepper, Straker e Pollock (2000) em estudo com engenheiros e designers, este estudo demonstrou a necessidade de incluir o ensino de ergonomia na formação dos designers de vestuário para melhorar o conhecimento dos designers e a aplicação da ergonomia no processo de desenvolvimento de produtos.

A etapa mais citada pelos participantes quando questionados sobre a aplicação da ergonomia no processo de produção do vestuário foi a modelagem. De fato, é nessa etapa que GEPROS. Gestão da Produção, Operações e Sistemas, v. 14, nº 2, p. 149 - 170, 2019. 
Ergonomia Aplicada ao Projeto do Produto: O Ponto de Vista de

Designers do Vestuário

são utilizados os dados antropométricos dos usuários, bem como é viabilizada a produção das peças. O conhecimento do corpo e de seus movimentos, conforme apontado por Jones (2011), é fundamental para a elaboração de roupas eficazes e confortáveis. A modelagem é uma etapa muito importante no processo de produção do vestuário, pois transforma o desenho técnico em moldes, os quais poderão seguir na linha de produção para o corte no tecido e a costura.

Essa etapa pode ser entendida como parte do desenvolvimento do produto. Portanto, poder-se-ia considerar que a aplicação da ergonomia na modelagem representa a utilização da ergonomia de concepção, considerada ideal por lida e Buarque (2016). Nesse sentido, as outras duas etapas mais citadas, após a modelagem, a prova dos produtos e a concepção, também correspondem à fase de inicial de desenvolvimento do produto. Por outro lado, os participantes, em alguns casos, afirmam que não aplicam a ergonomia no processo de produção de vestuário, pois, segundo eles, apenas desenham, criam. Vê-se, nesses casos, que a ideia de aplicação da ergonomia não está associada à criação do produto, mas sim à parte de engenharia, como costuma ser chamada a etapa subsequente ao desenho.

Em relação à obtenção e aplicação dos dados antropométricos dos usuários para o design do vestuário, cinco participantes afirmaram não terem envolvimento com essa questão. Parece haver relação entre esse não envolvimento e o porte da empresa, visto que três desses entrevistados trabalham em empresas de grande porte. Outra relação possível é com a forma de organização do processo dentro da empresa, pois, dos outros dois participantes que afirmam não se envolver com a obtenção e aplicação dos dados antropométricos do públicoalvo, um trabalha com consultoria para diversas empresas e outro trabalha com a terceirização da etapa de modelagem, ou seja, ela não acontece dentro da empresa. A importância da obtenção e aplicação de dados antropométricos precisos é reafirmada em diversos trabalhos, como o de Barroso et al. (2005), Poirson e Parkinson (2014), Skepper, Straker e Pollock (2000), Nishimura, Merino e Amaral (2016), Gruber e Alves (2011). Além disso, outra questão levantada por alguns participantes é a heterogeneidade da população e a ausência de padronização de medidas antropométricas de abrangência nacional, questão levantada nos trabalhos de Poirson e Parkinson (2014), Nishimura, Merino e Amaral (2016), Gruber e Alves (2011) e Sabrá et al. (2013). Nesta pesquisa, tanto a questão levantada por Jarosz (2000), quanto a problemática do trabalho de Widyantiet et al. (2015) estão presentes nos discursos dos entrevistados. Os estilistas ressaltam a necessidade de uma padronização de medidas no 
Ergonomia Aplicada ao Projeto do Produto: O Ponto de Vista de

Designers do Vestuário

Brasil, mas entendem que é uma tarefa difícil, devido ao tamanho do país e às diferenças regionais acentuadas.

Ainda em relação aos dados do público-alvo utilizados no processo de desenvolvimento de produtos, os participantes destacam a faixa etária e o histórico de vendas. O destaque para a faixa etária vai ao encontro do que foi citado em relação às diferenças existentes nas medidas antropométricas dos usuários. Além disso, envolve questões de estilo de vida, comportamento, hábitos de consumo, dentre outras que estão contidas na delimitação de idade do público-alvo. O histórico de vendas, citado por diversos participantes como um dos subsídios mais relevantes para o desenvolvimento de novas coleções, é evidenciado nas referências bibliográficas sobre o planejamento do processo de design de vestuário (SANCHES, 2014; TREPTOW, 2013; MATHARU, 2011).

\section{CONCLUSÕES}

O objetivo deste trabalho foi investigar a aplicação da ergonomia no processo de desenvolvimento de produtos do vestuário. Para isso, primeiramente foram coletadas opiniões de estilistas em relação ao conceito de ergonomia. A maioria dos participantes demonstrou ter uma compreensão do termo ergonomia adequada ao que é apresentado na literatura, relacionando-o a uma busca por adequar os produtos aos usuários e proporcionar uma interação confortável entre usuários e produtos.

Os participantes consideram que a ergonomia é aplicada no processo de desenvolvimento de produtos do vestuário, relacionando-a principalmente à etapa de modelagem e prova dos produtos. Percebeu-se que na maioria dos casos os estilistas não se sentem responsáveis por se preocupar com a aplicação da ergonomia nesse processo, relegando essa responsabilidade aos modelistas. A obtenção de dados antropométricos do público-alvo não é considerada pelos participantes como uma de suas atribuições. A maioria deles considera que esses dados não influenciam em seu trabalho.

Com base nos resultados obtidos e relacionando-os aos estudos prévios, considera-se que a hipótese do trabalho foi corroborada: os conhecimentos de ergonomia são aplicados no processo de desenvolvimento de produtos do vestuário de forma intuitiva pelos designers. Assumindo que os estilistas desempenham um papel fundamental no desenvolvimento dos produtos de vestuário, os quais, dependendo de seus atributos, podem gerar conforto ou 
desconforto, satisfação ou insatisfação aos usuários, é necessário investir mais na formação relacionada à ergonomia desses profissionais. 
Ergonomia Aplicada ao Projeto do Produto: O Ponto de Vista de Designers do Vestuário

\section{Referências}

BARDIN, L. Análise de conteúdo. São Paulo: Edições 70, 2011.

BARROSO, M. P.; AREZES, P. M.; COSTA, L. G.; MIGUEL, A. S. Anthropometric study of Portuguese workers. International Journal of Industrial Ergonomics, v. 35, n. 5, p.401410, 2005.

BOUERI, J. J. Sob medida: antropometria, projeto e modelagem. In: PIRES, D. B. (Org.). Design de moda: olhares diversos. Barueri: Estação das Letras e Cores, 2014.

BÜRDEK, B. E. Design: história, teoria e prática do design de produtos. 2. ed. São Paulo: Edgar Blücher, 2010.

GOMES FILHO, J. Design do objeto: bases conceituais. São Paulo: Escrituras, 2006.

GONÇALVES, E.; LOPES, L. D. Ergonomia no vestuário: conceito de conforto como valor agregado ao produto de moda. Moda palavra: reflexões em moda, v. 4, p.22-29, 2006.

GRUBER, C.; ALVES, A. S. Estudo comparativo entre tabelas de medidas femininas para modelagem. In: COLÓQUIO DE MODA, 7., 2011, Maringá. Anais.... Maringá: RedeModa, 2011. p. 1-10.

GUERRA, I. C. Pesquisa qualitativa e análise de conteúdo: sentidos e formas de uso. São João do Estoril: Princípia, 2012.

IIDA, I.; BUARQUE, L. Ergonomia: projeto e produção. 3. ed. São Paulo: Blucher, 2016.

JAROSZ, E. Anthropometry of elderly women in Poland: dimensions for design. International Journal of Industrial Ergonomics, v. 25, n. 2, p.203-213, 2000.

JONES, S. J. Fashion design: manual do estilista. 3. Ed. São Paulo: Cosac Naify, 2011.

KARWOWSKI, W.; MARRAS, W. S. (Eds.). Occupational ergonomics: engineering and administrative controls. Boca Raton: CRC Press, 2005.

MARTINS, S. B. Ergonomia e moda: repensando a segunda pele. In: PIRES, D. B. (Org.). Design de moda: olhares diversos. Barueri: Estação das Letras e Cores, 2014.

MARTINS, S. B. O conforto no vestuário: uma interpretação da ergonomia: metodologia para avaliação de usabilidade e conforto no vestuário. 2005. 150 f. Tese (Doutorado em Engenharia de Produção) - Universidade Federal de Santa Catarina, Centro Tecnológico. Florianópolis, SC, 2005.

MATHARU, G. O que é design de moda?. Porto Alegre: Bookman, 2011.

NEMETH, C. P. Human factors methods for design: making systems human-centered. London: CRC, 2004.

NISHIMURA, M. D. L.; MERINO, E. A. D.; GONTIJO, L. A. Referenciais de Medidas da ABNT: Instrumento para a normalização do produto de vestuário. Moda palavra, v. 10, $\mathrm{n}$. 19, p.135-149, 2016.

PASCHOARELLI, L. C. Conhecimento científico e a prática profissional da ergonomia: a contribuição da ergonomia física no design de produtos. In: BARBOSA, A. C. L. S.; RANGEL, M. M.; RAPOSO, M. (Org.). Ergonomia design usabilidade interação. Juiz de Fora: Mamm UFJF, 2013. p. 77-93. 
PIRES, D. B. O desenvolvimento de produtos de moda: uma atividade multidisciplinar. In: CONGRESSO BRASILEIRO DE PESQUISA E DESENVOLVIMENTO EM DESIGN, 6. 2004, São Paulo. Anais...São Paulo: Faap, 2004. p. 1 - 8.

POIRSON, E.; PARKINSON, M. Estimated anthropometry for male commercial pilots in Europe and an approach to its use in seat design. International Journal of Industrial Ergonomics, v. 44, n. 5, p.769-776, 2014.

RENFREW, E.; RENFREW, C. Desenvolvendo uma coleção. Porto Alegre: Bookman, 2010.

ROSA, L. Vestuário industrializado: uso da ergonomia nas fases de gerência de produto, criação, modelagem e prototipagem. 2011. 175 p. Tese (Doutorado em artes e design) Pontifícia Universidade Católica do Rio de Janeiro, Rio de Janeiro, 2011.

SABRÁ, F.; ROSA, R. A.; SANTOS, C. S.; BRITO, L. F. F. Desenvolvendo a nova referência de medidas para o vestuário através da tecnologia de escaneamento de corpos 3D. In: CONGRESSO INTERNACIONAL DE ERGONOMIA E USABILIDADE DE INTERFACES HUMANO-TECNOLOGIA, 13., 2013, Juiz de Fora. Anais...Juiz de Fora: UFJF, 2013. p. 1 - 7.

SANCHES, M. C. F. Projetando moda: diretrizes para a concepção de produtos. In: PIRES, D. B. (Org.). Design de moda: olhares diversos. Barueri: Estação das Letras e Cores, 2014.

SILVEIRA, I. Aplicação da ergonomia no projeto do vestuário. Moda palavra: reflexões em moda, Florianópolis, v. 4, p.12-19, 2006.

SKEPPER, N.; STRAKER, L.; POLLOCK, C. A case study of the use of ergonomics information in a heavy engineering design process. International Journal of Industrial Ergonomics, v. 26, n. 3, p.425-435, 2000.

TREPTOW, D. Inventando moda: planejamento de coleção. 5. ed. São Paulo: Edição da Autora, 2013.

WIDYANTI, A.; SUSANTI, L.; SUTALAKSANA, I. Z.; MUSLIM, K. Ethnic differences in Indonesian anthropometry data: evidence from three different largest ethnics. International Journal of Industrial Ergonomics, v. 47, p.72-78, 2015. 